\title{
Toma de decisiones y situación financiera en pequeños sistemas de agua potable: dos casos de estudio en El Cardonal, Hidalgo, México
}

\author{
Emmanuel Galindo Escamilla* \\ Jacinta Palerm Viqueira**
}

Resumen: ${ }^{1}$ en este artículo se presentan dos tipos de organizaciones que administran pequeños sistemas de agua potable: un comité de usuarios y un organismo operador. El objetivo es comparar la toma de decisiones y la situación financiera de los sistemas San Miguel Tlazintla y El Cardonal. El primero está a cargo de los usuarios, quienes realizan la operación y el mantenimiento, eligen un comité para la administración y establecen las cuotas que se cobran por el agua entubada. En el segundo, una junta de gobierno y un director general se encargan de contratar y dirigir al personal operativo y administrativo. Se concluye que el comité de usuarios cubre todos sus costos; por el contrario, el organismo operador recibe subsidios municipales.

\footnotetext{
* Estudiante del doctorado en antropología, Centro de Investigaciones y Estudios Superiores en Antropología Social (CIESAS), D. F. Correo electrónico: galindoesc@yahoo.com.mx

** Profesora-investigadora titular, Colegio de Postgraduados, Desarrollo Rural. Correo electrónico: jpalerm@colpos.mx

${ }^{1}$ Investigación realizada con el apoyo del proyecto CONACYT no. 79 201, “Juntas de agua, unidades de riego y otras organizaciones de regantes. Impacto de los cambios en la legislación sobre las capacidades autogestivas de los regantes". Se agradece a los árbitros anónimos sus comentarios, que permitieron mejorar el texto; a los comités del Sistema de Agua Potable San Miguel Tlazintla y al personal del organismo operador de El Cardonal, por las facilidades otorgadas para realizar la investigación de campo.
} 
Palabras clave: agua potable rural, manejo comunitario, comité de usuarios.

Abstract: this article compares two types of organizations which manage small water supply systems: one a consumer committee and the other an operating agency. The objective is to compare decision-making processes and financial situations between the two case studies: San Miguel Tlazintla and El Cardonal. In the first case study, operation and maintenance is in the hands of the consumers through an elected Committee, and the consumers establish the fees for service. In the second case study, the water system is managed by a Governance Committee and a General Manager who hire and direct the operational and administrative staff. Results show that the consumer committee covers all its costs through service fees, whereas the operating agency receives municipal subsidies.

Key words: rural drinking water, community management, consumer committee.

\section{Introducción}

De acuerdo con los supuestos teóricos del nuevo institucionalismo, en este documento se comparan dos tipos de organizaciones que manejan pequeños sistemas de agua potable: el Comité General para la Administración y Operación del Sistema de Agua Potable San Miguel Tlazintla, diseñado por los propios usuarios en un marco institucional informal, y el Organismo Descentralizado de Agua Potable y Alcantarillado de Cardonal, diseñado por el ayuntamiento correspondiente en el marco institucional formal, emanado de la legislación nacional y estatal vigente en materia de agua para uso doméstico, ambos se localizan en El Cardonal, un municipio del estado de Hidalgo, México. 
Muchas de las organizaciones que conforman los usuarios para el manejo de pequeños sistemas de agua potable operan al margen de la legislación vigente, por tanto carecen de reconocimiento legal por parte del Estado, pero en la práctica representan una opción eficiente y adecuada para espacios o escalas donde al Estado y a la iniciativa privada les resulta oneroso instalar su actual modelo basado en especialistas dirigidos por gerentes.

En la propuesta teórica del nuevo institucionalismo existen elementos para explicar la presencia y permanencia de organizaciones creadas por los propios usuarios, a fin de garantizar su abasto de agua. Al considerar a las instituciones como reglas de juego o limitaciones creadas por el hombre para dar forma a la interacción humana, Douglass North (2006, 13-14) dice que reducen la incertidumbre porque proporcionan una estructura a la vida diaria, que pueden ser formales o informales, y que estas últimas resultan económicas y eficientes sin importar que carezcan de reconocimiento legal.

Así, los acuerdos no escritos, los cargos honoríficos, los reglamentos comunitarios u otras reglas o limitaciones creadas por los usuarios de sistemas de agua para uso doméstico se definen como instituciones informales. Lo anterior, porque las variadas respuestas humanas para satisfacer el abasto de agua son vistas, en los pequeños pueblos, como un mecanismo que da certidumbre y que estructura la vida diaria en relación con las necesidades comunitarias, familiares e individuales en torno al recurso.

En el estudio de los recursos de uso común, otra vertiente del nuevo institucionalismo, se correlaciona la creación de instituciones por parte de los usuarios y el manejo de obras hidráulicas. De acuerdo con Elinor Ostrom (2000, 65-70 y 80-82), el agua y la infraestructura necesaria para emplearla tanto en sistemas de riego como de agua potable se definen como recursos de uso común, por tanto, se supone que los arreglos institucionales diseñados por los usuarios resultan una tercera vía, además del Estado y el mercado, para el manejo eficiente de los pequeños sistemas de agua para consumo doméstico.

Desde el siglo XIx surgió el interés por estudiar las capacidades de gestión no burocrática, y el ejemplo más destacado de ello corres- 
ponde a la llamada comunidad aldeana (Maine 1980; De Laveleye 1878). Pero en ese mismo siglo también se propuso que la propiedad privada y el mercado podían ser los mecanismos más eficientes para la prosperidad de las naciones (Smith 2000). Ahora se ha dado un giro al plantear que las comunidades aldeanas son formas de gestión pertinentes y eficaces para el manejo de recursos, entre ellos el agua para consumo humano o la producción agrícola (Wade 1988; Agarwal y Narain 1991; Agarwal et al. 2001).

Este documento se divide en tres apartados; en el primero se bosqueja el proceso de modernización de los pequeños sistemas de agua potable y se presenta el marco legal vigente, nacional y estatal, en materia de agua para uso doméstico. En el segundo se abordan los estudios de caso, en el tercero se compara la toma de decisiones para seleccionar al personal, así como para establecer los criterios de acceso y exclusión del sistema, y la situación financiera de cada organización a partir del tipo y monto de las tarifas que cobra y su capacidad para cubrir sus gastos fijos con sus ingresos fijos.

Legislación y abasto de agua potable en pequeños pueblos

En 1934, el gobierno federal mexicano inició una política de salud pública con el objetivo de modernizar el abasto de agua para uso doméstico en las zonas rurales, para ello se introdujo la tubería en red y se benefició a los centros de población de menos de 2500 habitantes, que no fueran cabeceras municipales (Secretaría de Salubridad y Asistencia, SSA 1965, 1; Secretaría de Recursos Hidráulicos, SRH 1976, 143; Secretaría de Programación y Presupuesto, SPP 1985a, 226 y 315 ; Birrichaga 2007, 211).

Las dependencias que ejecutaron tal política, entre 1934 y 1980 , fueron el Departamento de Salubridad, después ssa (Bribiesca 1959, 100 y 104; SSA 1965, 1; SPP 1985a, 249); el Departamento de Asuntos Indígenas, después Instituto Nacional Indigenista, INI; (Aguirre Beltrán 1992, 180 y 1994, 206; iNi 1955, 50 y 1964, 58-64); el Departamento Agrario, después Secretaría de Agricultura (Bribies- 
ca 1959, 104); la SRH, a través de su rama de ingeniería sanitaria (SPP 1985b, 575) y la Coordinación General del Plan Nacional de Zonas Deprimidas y Grupos Marginados, Coplamar $(1980,14)$, en coordinación con la Secretaría de Asentamientos Humanos y Obras Públicas (SAHOP).

La SRH construyó y manejó los sistemas de agua potable a través de las juntas federales de agua potable, pero una vez que recuperaba la inversión los entregaba a los ayuntamientos. ${ }^{2}$ Caso contrario, los sistemas que construyó la SSA se entregaron a los pueblos beneficiados y con diez usuarios se conformó una Junta rural de agua potable para su administración, operación, mantenimiento y ampliación (SSA 1965, 2).

Las regiones conocidas como Valle del Mezquital, en Hidalgo, y los Altos, en Chiapas, representan casos en donde la SRH entregó los sistemas a los usuarios. En la primera fueron construidos en cooperación con el Patrimonio Indígena del Valle del Mezquital (PIVM) (Marzal 1968, 86), y en la segunda con el INI (Köhler 1975, 274; Burguete 2001, 92-97).

Durante las décadas de 1980 y 1990 se registró una serie de cambios en la legislación, que hizo de competencia exclusiva de los municipios la administración de las aguas para uso doméstico, y con ello les quitaron capacidad jurídica a los pueblos para administrar dichas aguas. Tal cambio en la política pública inició en octubre de 1980 con el acuerdo de entrega, a los gobiernos de los estados o a los ayuntamientos, de todos los sistemas de agua potable y alcantarillado que desde 1949 manejaban las Juntas federales de agua potable, que sumaban 1413 , que se dice abastecían a 2100 centros de población en todo el país (SAHOP 1981, 9 y 20-42). Algunos de esos sistemas fueron construidos a partir de 1933 con créditos del Banco Nacional Hipotecario Urbano y de Obras Públicas, en el marco de una política nacional, para apoyar la modernización de los sistemas de agua potable de las ciudades (Bribiesca 1959, 100-103; Aboites 1998, 161; Pineda 2002, 45), pero que por razones diversas en los

\footnotetext{
${ }^{2}$ Artículo 5 de la Ley Federal de Ingeniería Sanitaria [1948], el Reglamento de las Juntas federales de agua potable [1949] y el artículo 34 de la Ley Federal de Aguas [1971] (Lanz Cárdenas 1982, 283-288, 833-848 y 389-439).
} 
convenios de entrega-recepción se incluyeron pequeños sistemas para poblados rurales.

La legislación crítica es la reforma al artículo 115 constitucional, emitida el 3 de febrero de 1983, que le asigna a los municipios, como una más de sus atribuciones, el abasto del servicio público de agua potable y alcantarillado en su jurisdicción territorial (Tena 2002, 1022), y para ello se incluyó en la estructura de la administración municipal una dirección encargada del manejo de los sistemas de agua potable a cargo del ayuntamiento.

Además, en 1992, a los ejidos y comunidades agrarias se les quitaron atribuciones con la nueva Ley Agraria. Así, a partir de esa fecha los asuntos de aguas de tales centros de población se rigen por la Ley de Aguas Nacionales (LAN) de 1992, que está vigente y establece tres modalidades de acceso a las aguas de propiedad nacional: libre, asignación y concesión. ${ }^{3}$

Las aguas para uso doméstico se otorgan por asignación y será siempre a nombre del municipio, el que a su vez puede concesionar la administración. Y en los casos en que la concesione a ejidos, comunidades u organizaciones de colonos o de usuarios, éstos deben constituir una persona moral con ese fin específico y adjuntar a su solicitud la copia de su acta constitutiva. ${ }^{4}$ Por alguna razón el ejido no se considera en esta legislación una persona moral.

En agosto de 2002 se reformó el Reglamento de la LAN, y en diciembre de 2003 la propia ley. Dicha reforma sólo introdujo modificaciones en lo relativo al tiempo de vigencia máximo, que se redujo de 50 a 30 años, y de las asignaciones y concesiones, así como la forma de solicitar su renovación, que en caso de no pedir la prórroga en el plazo establecido se pierde tal concesión o asignación. ${ }^{5}$

Según el marco legal descrito, es común encontrar que en los municipios de México la administración, operación y mantenimiento de pequeños sistemas de agua entubada que abastecen a po-

\footnotetext{
${ }^{3}$ Véase los artículos 1 y 2 de la Ley Agraria de 1992 (Procuraduría Agraria 1993). Y los artículos 3, 17, 18 y 20 de la LAN de 1992 (Comisión Nacional del Agua, CONAGuA 1994).

${ }^{4}$ Véase el artículo 44 de la LAN y los artículos 18, 29, 31, 32, 81, 82 de su reglamento (CONAGUA 1994, 44, 89, 95, 96, 97 y 115).

${ }^{5}$ Véase el artículo 24 de la LAN vigente a partir de 2004. Ley de Aguas Nacionales y su reglamento, 51-52 (CONAGUA 2004).
} 
blados rurales esté a cargo de dos tipos de organizaciones emanadas de la legislación vigente: la dirección municipal del agua potable o el organismo operador descentralizado del municipio. Pero también es común la presencia de comités de usuarios, los cuales en general operan al margen de la legislación en materia de aguas.

Legislación y abasto de agua potable en Hidalgo

El trámite específico para que los pueblos administren las aguas para uso doméstico depende de las leyes federales y estatales en materia de aguas. La variación entre las legislaciones estatales, en función de que faciliten o dificulten la auto administración puede ser significativa, tal y como lo sugiere un contraste inicial entre la de Hidalgo, Morelos y Tlaxcala. Sin embargo, por el momento, la de Hidalgo es la que compete a los estudios de caso realizados en este trabajo.

El 30 de diciembre de 1999 se emitió la Ley Estatal de Agua y Alcantarillado para el Estado de Hidalgo, y se creó la Comisión Estatal del Agua y Alcantarillado como un organismo público descentralizado con personalidad jurídica y patrimonio propio. Sus objetivos son coordinar las acciones relacionadas con la explotación, uso y aprovechamiento del agua, y la descentralización de los servicios de agua en el estado (Periódico Oficial del Estado de Hidalgo, POEH 1999). Para ello define al abasto de agua para uso doméstico como un servicio público que estará a cargo de prestadores de servicios. ${ }^{6}$

El 10 de julio del año 2000 se emitió el reglamento de dicha ley, y se especificó que en Hidalgo sólo se reconocen cinco tipos de prestadores del servicio público de agua y alcantarillado: a) los municipios; b) los organismos operadores municipales; c) los organismos operadores intermunicipales; d) la comisión estatal del agua

\footnotetext{
${ }^{6} \mathrm{Al}$ respecto, la Ley Estatal de Agua Potable y Alcantarillado del Estado de Hidalgo dice lo siguiente: “Artículo 3. Para los efectos de esta Ley se entenderá por: [...];VII. Concesionario: la persona moral a la que se concesionen los servicios públicos de agua; [...] xviII. Prestador de los servicios: quien preste los servicios públicos de agua potable y alcantarillado, saneamiento, drenaje pluvial, ya sean, los Municipios, Organismos Operadores Municipales, Intermunicipales, o Concesionarios o la propia Comisión; [...] xxiII. Servicios públicos: los servicios públicos de agua potable y alcantarillado, incluyendo, la potabilización, conducción y distribución de aguas, y conducción, alojamiento y disposición final de las aguas del alcantarillado sanitario y pluviales" (РОЕH 1999).
} 
y e) los concesionarios (Ibid., 2000). En el primero, el municipio está obligado a pagar las contribuciones en materia de agua potable y tiene las facultades para recibir todas las obras que se construyan en su jurisdicción territorial, y para abastecer a todos los centros de población que lo conforman, lo mismo que aplicar las sanciones enunciadas en la ley estatal y su reglamento, así como para seleccionar al personal técnico y administrativo que manejará los sistemas de agua entubada. No obstante, carece de autonomía para establecer las tarifas que cobra por el servicio, ya que éstas deben ser aprobadas por el Congreso del estado. La ley estatal faculta a los municipios para descentralizar el servicio de agua potable o para concesionarlo a terceros. ${ }^{7}$

El abasto de agua está a cargo de organismos operadores en los municipios donde su localidad principal rebasa los 2500 habitantes, para ello debe existir un acuerdo previo del ayuntamiento respectivo y se constituyen como un organismo público descentralizado de la administración pública municipal, con personalidad jurídica y patrimonio propio. Están facultados para construir y manejar sistemas de agua potable; la infraestructura hidráulica, los edificios, vehículos y equipos que utilizan son de su propiedad y no del municipio en tanto tales bienes integran su patrimonio. Además, contratan directamente sus créditos, son los únicos responsables de los adeudos contraídos y se conforma por una junta de gobierno y un director general. $^{8}$

En el papel, este tipo de prestador de servicios está descentralizado de la administración del municipio, pero en la toma de decisiones permanece subordinado al presidente municipal en turno, ya que éste encabeza la Junta de gobierno, y puede designar y remover de su puesto al director general. Como requisito principal, este último debe ser mexicano y tener experiencia técnica, administrativa y profesional en materia de agua. ${ }^{9}$ En las finanzas están subordinados al Congreso estatal, porque es el que aprueba las tarifas.

\footnotetext{
${ }^{7}$ Artículos 25, 27, 28 y 29 de la Ley Estatal de Agua Potable y Alcantarillado del Estado de Hidalgo (POEH 1999).

${ }^{8}$ Artículos 30-40 de la Ley Estatal de Agua Potable y Alcantarillado del Estado de Hidalgo (РОен 1999).

${ }^{9}$ Véase el artículo 38 de la Ley Estatal de Agua Potable y Alcantarillado del Estado de Hidalgo (POEH 30/12/ 1999).
} 
La Ley de Agua Potable y Alcantarillado del Estado de Hidalgo establece la posibilidad de que los organismos operadores municipales e intermunicipales se constituyan como sociedades anónimas, los primeros bajo el régimen de empresas de participación estatal y los segundos como empresas de participación estatal o municipal. Cuando es el caso, a tales sociedades anónimas las rigen la legislación mercantil y la ley orgánica municipal, y así los ayuntamientos pueden vender las acciones representativas de su capital social. ${ }^{10}$

En Hidalgo, los usuarios pueden participar en la prestación de los servicios públicos, la ejecución de obras de infraestructura hidráulica y en la construcción, administración, operación y mantenimiento total o parcial de los sistemas destinados a ello. Para hacerlo necesitan una concesión que otorga el municipio, los organismos operadores municipales, intermunicipales o la comisión estatal, y se emite a nombre de personas morales. En el caso específico de las comunidades rurales, la misma ley señala que tal concesión será

${ }^{10} \mathrm{Al}$ respecto, la ley citada dice lo siguiente: “Artículo 44. Los Organismos Operadores Municipales podrán constituirse como sociedades anónimas bajo el régimen de empresas de participación municipal, en cuyo caso el capital social deberá suscribirse mayoritariamente por el Municipio o por Entidades de la Administración Pública Municipal; Artículo 45. La constitución, organización y funcionamiento de las sociedades anónimas con capital mayoritariamente público, se regirá por la Legislación Mercantil y la Ley Orgánica Municipal. Asimismo, se les aplicará en lo conducente lo dispuesto por los artículos 33, 34, 35 y 40 de esta Ley. Las disposiciones relativas a la Junta de Gobierno se entenderán referidas al Consejo de Administración; Artículo 46. En caso de que los Organismos Operadores Municipales o Intermunicipales se constituyan como sociedades anónimas en la forma que se refiere el artículo anterior, el o los Ayuntamientos de los Municipios podrán acordar la venta parcial de las acciones representativas de su capital social, previa licitación pública, de conformidad con lo establecido en el artículo 63 de este ordenamiento legal. Cuando el sector social o privado detenten más del 50\% de las acciones representativas del capital social, se dejará de aplicar a la sociedad de que se trate las disposiciones de este Capítulo y se les aplicará lo relativo a las concesiones. El Municipio deberá otorgar por licitación pública, la concesión respectiva para lo cual deberá atender, en lo conducente, a lo establecido en los artículos 64 y 65 de esta Ley, así como a la legislación local aplicable; [...] Artículo 51. Los Organismos Operadores Intermunicipales [...] también podrán constituirse como sociedades anónimas bajo el régimen de empresas de participación estatal o municipal, en cuyo caso el capital social será mayoritariamente por los Municipios o entidades de las administraciones públicas municipales correspondientes. Los Municipios deberán otorgar por adjudicación la concesión respectiva, para lo cual deberán atender, en lo conducente, a lo establecido en los artículos 62 y 63 de esta Ley, así como a la legislación local aplicable. De constituirse los Organismos Operadores Intermunicipales conforme a este párrafo, serán aplicables los artículos 45 y 46 de este ordenamiento legal” (POEH 1999). 
otorgada por el ayuntamiento respectivo a las organizaciones que se constituyan y que así lo soliciten. ${ }^{11}$

Según el esquema descrito, la legislación de Hidalgo permite a los usuarios de pequeños pueblos el manejo de los sistemas, con los que se abastecen de agua para uso doméstico.Y como se establece en la ley estatal, dicha concesión debe ser aprobada por el Congreso y sólo tendrá una vigencia de 30 años, al término los usuarios deben solicitar una prórroga al ayuntamiento otorgante y éste se reserva el derecho de conferirla. ${ }^{12}$

Por tanto, si un comité de usuarios se constituye como una persona moral adquiere el carácter de prestador del servicio público y, previa aprobación del Congreso, puede recibir dicha concesión bajo los términos siguientes:

Artículo 64. El título de concesión deberá contener, entre otros: I. Los fundamentos jurídicos y su objetivo; II. La descripción de la autoridad concedente y del concesionario; III. Los derechos y obligaciones de los concesionarios; iv. El monto de la garantía que otorgue el concesionario; v. Las contraprestaciones que deban cubrirse al concedente; vi. Las obligaciones del concedente; VII. Las garantías que otorgue el concesionario al concedente; viII. La indemnización que el concedente otorgue al concesionario en caso de revocación de la concesión [...]; ix. El período de vigencia; x. La descripción de los bienes, obras e instalaciones que se concesionan [...]; XI. Las reglas y características de la prestación de los servicios públicos; xII. El señalamiento del área geográfica donde el concesionario debe prestar los servicios públicos; XIII. Las metas de cobertura y eficiencia técnicas, físicas y comerciales; xIv. Los programas de construcción, expansión y modernización de los sistemas [...]; xv. Las fórmulas para calcular las cuotas y tarifas [...]; xvi. El reconocimiento explícito a la Comisión como árbitro en caso de controversia entre las partes;

${ }^{11}$ Artículos 61, 62 y 63 de la Ley Estatal de Agua Potable y Alcantarillado del Estado de Hidalgo (POEH 1999).

12 Artículo 65 de la Ley Estatal de Agua Potable y Alcantarillado del Estado de Hidalgo (POEH 1999). 
y como autoridad en el ejercicio de las atribuciones que se le confieren en la presente Ley, en el título de concesión o cualquier otro ordenamiento cuando el concedente sea el Municipio, Organismos Operadores Municipales e Intermunicipales y xvII. Las causas de revocación a que se refiere el artículo 71 1" (POEH 1999).

\section{Los casos de estudio}

El municipio de El Cardonal se ubica al centro de Hidalgo; en 2010 contaba con una población de 16943 personas agrupadas en 92 lo-

\section{Figura 1}

Organizaciones para el abasto de agua en el municipio de El Cardonal, Hidalgo

\begin{tabular}{|l|c|l|}
\hline Organización & Fuente de agua & \multicolumn{1}{|c|}{ Localidades que atiende } \\
\hline Organismo operador & Pozo profundo & $\begin{array}{l}\text { El Cardonal, El Buena, Cerritos, Piedra } \\
\text { Chica, El Vithe, Cardonalito, Colonia } \\
\text { Colosio, San Antonio Sabanillas }\end{array}$ \\
\hline Comité comunitario & Pozo profundo & Emilio Hernández (La Florida) \\
\hline Comité comunitario & Pozo profundo & El Bingo y San Antonio Sabanilla \\
\hline Comité comunitario & Pozo profundo & Cerro Colorado \\
\hline Comité comunitario & Pozo profundo & El Deca \\
\hline Comité comunitario & Pozo profundo & Cieneguillita \\
\hline Comité comunitario & Manantial & San Clemente \\
\hline Comité comunitario & Manantial & Santuario Mapethe \\
\hline Comité comunitario & Manantial & Pilas Yonthé \\
\hline Comité comunitario & Manantial & Pinalito \\
\hline Comité comunitario & Manantial & Los Fresnos \\
\hline Comité multicomunitario & Manantial & $\begin{array}{l}\text { Cuesta Blanca, El Bóndho, San Miguel } \\
\text { Tlazintla, El Sáuz, Durango Daboxtha, } \\
\text { Santa Teresa Daboxtha, San Andrés } \\
\text { Daboxtha, Pozuelos }\end{array}$ \\
\hline
\end{tabular}

* Incluye 15 viviendas, el resto se abastece de otros sistemas.

Fuente: elaborado con información proporcionada por el director del organismo operador de El Cardonal. 
calidades y un total de 3676 viviendas habitadas, de las cuales 70.4 por ciento tenía el servicio de agua entubada (Instituto Nacional de Estadística y Geografía, INEGI 2011). El director del organismo operador informó que en el municipio existen 12 sistemas de agua entubada, y que maneja sólo uno y el resto está a cargo de los comités de usuarios (véase figura 1).

Sistema El Cardonal

En cumplimiento con las disposiciones de la legislación federal y estatal, el 11 de marzo de 2001 se creó el Organismo Descentralizado de Agua Potable y Alcantarillado de Cardonal, con el Registro Federal de Contribuyentes MOH010312Q42. En su conjunto, el sistema se terminó de construir en 1999 (Secretaría de Gobierno del Estado de Hidalgo, SEGOB-HGO 2004) y en diciembre de 2008 abastecía a 650 tomas servidas, 641 domésticas y 9 comerciales (véase figura 2).

\section{Figura 2}

Tomas servidas por el organismo operador de El Cardonal

\begin{tabular}{|l|c|}
\hline Localidad & Tomas servidas \\
\hline El Cardonal & 225 \\
\hline Cardonalito & 27 \\
\hline Cerritos & 64 \\
\hline Colonia Colosio & 10 \\
\hline El Buena & 212 \\
\hline Piedra Chica & 34 \\
\hline San Antonio Sabanillas & 15 \\
\hline El Vithe & 63 \\
\hline Total & 650 \\
\hline
\end{tabular}

Fuente: elaborado con información proporcionada por el director del organismo operador de El Cardonal.

El equipo de bombeo instalado en el pozo trabaja de 6:00 a 16:00 horas durante toda la semana. En El Cardonal el abasto de 
agua se hace toda la semana las 24 horas del día, al resto de localidades el servicio se les otorga cada tercer día, generalmente de 13:00 a 17:00 horas.

Antecedentes del abasto de agua entubada

En la década de 1960 se construyeron los primeros dos sistemas de agua potable del municipio: El Pinal y San Miguel Jigui. Con el primero se abastecieron cinco pueblos: El Pinal, San Miguel Tlazintla, El Sáuz, San Andrés Daboxtha y Santa Teresa Daboxtha, y con el segundo San Miguel Jigui, El Decá, Cerro Colorado Bingu y San Antonio Sabanillas (SRH 1961). Los fondos para su construcción los aportaron el PIVM, la SRH y los usuarios beneficiados (Ibid.).

El director del organismo operador señaló que hasta 1999 el abasto de agua en la cabecera municipal se hacía con las aguas del manantial San Juan, localizado en Santuario Mapethe, que los habitantes pagaban las cuotas establecidas por el comité comunitario de Santuario y que le daban mantenimiento a la red de conducción.

Situación actual

El organismo operador descentralizado tiene a su cargo un pozo profundo, cinco tanques de almacenamiento y una red de tubería para la distribución domiciliaria del agua. El pozo se denomina La Vega, fue asignado al municipio de El Cardonal por la CONAGUA y está inscrito en el Registro Público de Derechos de Agua (REPDA) desde 2003, con el número 13HGO105648/26HMGE03. ${ }^{13}$

Estructura administrativa

Como se observa en la figura 3, para la operación y administración del sistema se contrataron ocho personas de tiempo completo. El presidente municipal en turno, quien también preside la Junta de gobierno del organismo operador, toma las decisiones referentes

\footnotetext{
${ }^{13}$ El número de registro se puede consultar en la base de datos digital del REPDA: http:// www.conagua.gob.mx/REPDA/anexos.aspx?Id=13HGO105648/26HMGE03 |0 0 2 |S
} 
a quién ocupa el cargo de director y por cuánto tiempo. A su vez, este último propone al subdirector, secretaria, los dos fontaneros, el pocero, el técnico y su ayudante.

El personal labora de martes a sábado de 8:30 a 16:00 horas y de 8:30 a 13:00 los domingos. El lunes se descansa, porque ese día se realiza el tianguis semanal en Ixmiquilpan, cabecera de un municipio vecino y principal centro de comercio de esa zona. El pocero labora toda la semana y su jornada es de 6:00 a 16:00 horas.

Durante los ocho años de operación del sistema, la rotación del personal operativo ha sido nula; el técnico que se contrató desde el inicio se mantiene en el puesto y los fontaneros tienen siete años de antigüedad. Por el contrario, la rotación del personal administrativo es alta, porque cada tres años que cambia la autoridad municipal también se sustituye al director, subdirector y a la secretaria.

\section{Figura 3}

Estructura del organismo operador de El Cardonal, Hidalgo

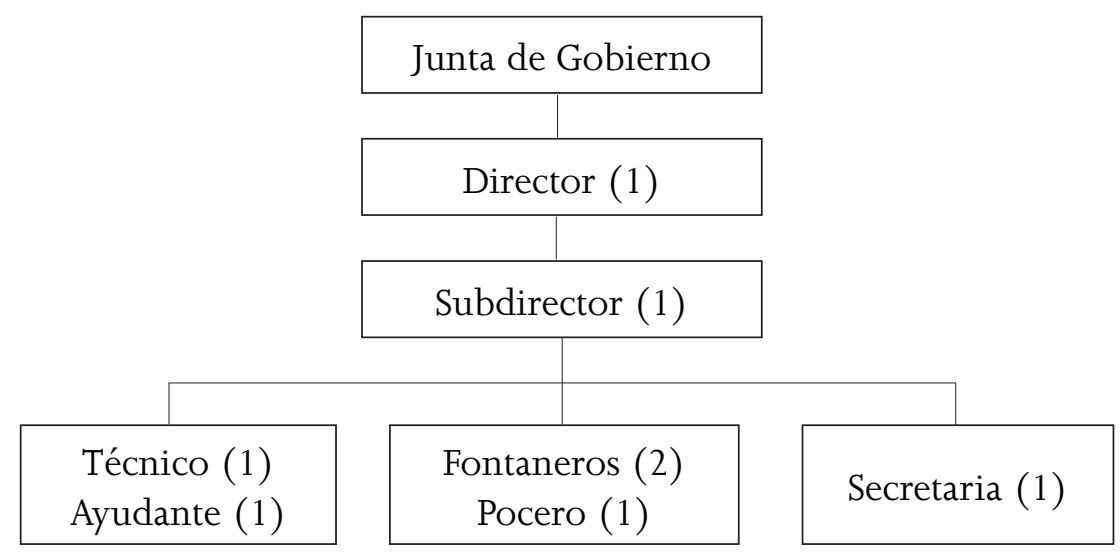

Fuente: elaborado con información proporcionada por el director del organismo operador de El Cardonal.

Actividades para el manejo del sistema

Le corresponde a la Junta de Gobierno elaborar el presupuesto anual del organismo operador, y enviar al Congreso el proyecto de 
tarifas para el cobro del servicio de agua entubada, con el objeto de que lo apruebe y publique en el POEH. El director general tiene la obligación de elaborar el presupuesto anual, coordinar las actividades diarias, programar y acudir a las reuniones ordinarias que celebra cada tres meses la Junta de Gobierno, adquirir los materiales y equipos necesarios para el mantenimiento o rehabilitación de la infraestructura del sistema, contratar a técnicos especializados cuando se presentan desperfectos mayores en el equipo de bombeo, pagar cada mes el consumo de energía eléctrica del pozo así como la nómina del personal empleado.

El subdirector y la secretaria son los únicos que están en la oficina la mayor parte del tiempo. Se encargan de realizar el cobro mensual por el servicio de agua entubada, calcular y cobrar los recargos que se generan cuando un usuario se retrasa con sus pagos, atender los trámites de solicitud de contrato para instalar una nueva toma de agua. Además, la secretaria lleva el control de ingresos y egresos. Cabe señalar que se contrata un despacho contable para que haga las declaraciones fiscales.

Para cumplir con las funciones asignadas, el pocero debe mantener en marcha el equipo de bombeo de 6:00 a 16:00 horas, durante la extracción y bombeo de agua a los tanques de almacenamiento debe aplicar las dosis correctas de cloro para potabilizar el agua, y también debe vigilar el correcto funcionamiento del equipo.

Los fontaneros son los encargados de: a) abrir y cerrar las válvulas de distribución del agua instaladas en los tanques de almacenamiento, desde los cuales se abastece cada tercer día a Cardonalito, Cerritos, Colonia Colosio, El Buena, Piedra Chica, San Antonio Sabanillas y El Vithe; b) realizar la lectura mensual del consumo de agua que se hace en cada una de las tomas servidas; c) reparar las fugas de agua en la red de conducción y distribución; d) instalar nuevas tomas de agua potable cuando se solicitan y e) lavar los tanques de almacenamiento cuando se requiera.

El técnico y su ayudante reparan las válvulas de distribución del agua cuando se averían o las cambian cuando ya no sirven, dan mantenimiento al equipo de bombeo instalado en el pozo y cuando el sistema sufre desperfectos considerables apoyan a los fontaneros en su reparación. 
Requisitos para ser usuario

Solicitar un contrato en las oficinas del organismo operador, proporcionar copias de la credencial de elector y del pago de predial o en su defecto de las escrituras del predio al que se le va a dotar del servicio, entregar un croquis de localización del predio donde se instalará la nueva toma de agua y una constancia del delegado municipal -representante legal de la localidad- donde se indique que el solicitante no tiene adeudos en la comunidad, pagar el costo del contrato que asciende a dos mil pesos, comprar el material necesario para conectar la toma, y hacer una excavación para descubrir la red de distribución en el punto donde se hará la conexión respectiva.

Las personas no nacidas en alguna de las localidades que atiende el organismo operador, y que soliciten una toma, deben cumplir los requisitos señalados y negociar con el delegado municipal en turno las condiciones en que serán avecindados en la localidad de que se trate. Cuando un solicitante, ya sea originario o avecindado, no cuenta con la constancia del delegado municipal respectivo no se le concede el contrato. Cumplidos los requisitos, el usuario y el director firman el contrato y el servicio deberá prestarse en un plazo no mayor de diez días.

El usuario se compromete a pagar en los primeros diez días de cada mes en las oficinas, sin necesidad de notificación. Quien no paga la mensualidad correspondiente se hace acreedor al cobro de diez pesos por concepto de recargos y a una multa de 200 pesos cuando adeuda un mes. El caso extremo es el estipulado en la cláusula sexta del contrato, y es cuando se suspende el suministro a quien adeude dos o más mensualidades consecutivas, acto seguido se cancela su contrato y para que le reanuden el servicio debe solicitar y pagar un nuevo contrato, así como 200 pesos por reconexión a la red de distribución.

Situación financiera

Las tarifas por el servicio de agua entubada que el Congreso estatal aprobó para el ejercicio fiscal 2009 fueron las siguientes: tomas 
domésticas, 50 pesos por un consumo de hasta $10.0 \mathrm{~m}^{3}$ de agua por mes y seis por cada metro cúbico adicional; tomas comerciales, 150 pesos al mes por un consumo de hasta $20 \mathrm{~m}^{3}$ y 13 por cada metro cúbico adicional.

De acuerdo con el director, la eficiencia en el cobro de las tarifas es de 100 por ciento, por lo tanto se tomó como promedio el consumo tope de $10 \mathrm{~m}^{3}$ y $20 \mathrm{~m}^{3}$ y se estimó que el organismo operador obtiene ingresos fijos mensuales por 33400 pesos (32050 por tomas domésticas y 1350 por comerciales). Según el director general, los costos fijos mensuales ascienden a 105400 pesos y comprenden el pago de la nómina, de la energía eléctrica que consume el pozo, la renta de oficinas y el pago del servicio telefónico (véase figura 4).

\section{Figura 4}

Situación financiera del organismo operador de El Cardonal en un mes promedio

\begin{tabular}{|c|c|c|c|c|}
\hline Tarifa (pesos) & Tomas & $\begin{array}{c}\text { Ingresos } \\
\text { (pesos) }\end{array}$ & Concepto & $\begin{array}{c}\text { Egresos } \\
\text { (pesos) }\end{array}$ \\
\hline Doméstica 50 & 641 & 32050 & Energía eléctrica del pozo & 60000 \\
\hline Comercial 150 & 9 & 1350 & Renta de oficinas & 5000 \\
\hline Ingreso total & & 33400 & Teléfono & 1000 \\
\hline & & & Director & 10000 \\
\hline & & & Subdirector & 6000 \\
\hline & & & Secretaria & 3600 \\
\hline & & & Técnico & 5000 \\
\hline & & & Ayudante técnico & 4000 \\
\hline & & & Fontaneros $(2 \times \$ 3600)$ & 7200 \\
\hline & & & Pocero & 3600 \\
\hline & & & Egresos totales & 105400 \\
\hline & & & Saldo mensual & -72000 \\
\hline
\end{tabular}

Fuente: elaboración propia, con información proporcionada por el director del organismo operador de El Cardonal.

Los datos de la figura 4 indican que el organismo operador tiene un déficit presupuestal de -72 mil pesos por mes, sin incluir los 
ingresos por recargos, multas o expedición de contratos. A decir del director general, el pago mensual de la energía eléctrica que consume el pozo lo hace el Ayuntamiento de El Cardonal y de esa manera se elimina el déficit. Según las cifras de la misma figura, se estimó que el pago por energía eléctrica para el pozo representa 56.9 por ciento del gasto mensual y 37.3 la nómina del personal. En otras palabras, los dos rubros suman 94.2 por ciento de los costos fijos por mes.

Al separar los gastos promedio mensuales de 60 mil pesos por energía eléctrica y 39400 por la nómina, y compararlos con los 33400 de ingresos, se concluye que el total de la recaudación al mes del organismo operador de El Cardonal por la prestación del servicio de agua entubada sólo alcanza para cubrir 84.77 por ciento de la nómina mensual o, en su defecto, 55.66 del pago por la electricidad. Entonces, se puede afirmar que dicha institución no es sostenible en el largo plazo.

Al dividir los gastos fijos entre el total de tomas servidas resulta que el costo mensual del personal es de 60.61 pesos y la energía eléctrica de 92.30. Por lo tanto, el titular de una toma debería de pagar, cuando menos, 153 pesos por mes para garantizar el pago de los dos conceptos. El monto de la tarifa estimada es muy superior a los 50 pesos que pagan hasta por $10 \mathrm{~m}^{3}$ de agua las tomas domésticas, y bastante cercano a los 150 de los usuarios comerciales.

Con la información presentada, se puede decir que en Hidalgo los organismos operadores carecen de autonomía para el manejo de los sistemas de agua potable, aun cuando son entidades descentralizadas de la administración municipal y estatal. Esto se debe a que en la toma de decisiones están sujetos a lo que determine su Junta de gobierno, lo cual se traduce en subordinación al presidente municipal en turno, y en lo financiero están subordinados al Congreso estatal, ya que éste aprueba el tipo y el monto de las tarifas que deben cobrar.

También se puede decir que el modelo gerencial y descentralizado propuesto por la legislación vigente no resulta adecuado en todos los casos. Una razón de ello es que la estrategia de agregar pueblos pequeños a una administración central, con el objetivo de alcanzar economías de escala o de aglomeración, no necesariamente se traduce en eficiencia financiera. Así, en el caso estudiado, el 
ayuntamiento cubre el déficit presupuestal del organismo operador de El Cardonal, pero los usuarios absorben el costo del personal empleado. Los datos presentados son suficientes para afirmar que, el hecho de que dicho organismo sea una organización diseñada según el marco legal vigente no contribuye a su eficiencia financiera.

Sistema de Agua Potable San Miguel Tlazintla

Al centro del municipio de El Cardonal se localiza un pequeño valle sobre el que se asientan Cuesta Blanca, El Bóndho, San Miguel Tlazintla, El Sáuz, Durango Daboxtha, Santa Teresa Daboxtha, San Andrés Daboxtha y Pozuelos, que desde 1965 reciben el servicio del Sistema San Miguel Tlazintla, cuya administración y operación está a cargo de diez comités de usuarios, un comité general, un consejo de vigilancia y el comité local. Todos se conforman por cargos honoríficos y se rotan cada dos años entre los habitantes de las comunidades.

La fuente de abasto de agua, el manantial Salinas, está en El Encino $y$ al fondo de un arroyo intermitente denominado Arroyo Hondo. El agua se retiene en un contenedor de concreto que los usuarios construyeron justo donde brota el manantial, y se conduce por una línea de tubería hasta un tanque de almacenamiento ubicado en Cuesta Blanca, desde donde, por la fuerza de gravedad y siguiendo la pendiente natural del terreno, el agua se distribuye a cada una de las ocho localidades, lo cual es posible porque entre el manantial y el tanque de almacenamiento existe un desnivel de -50 metros de altura y entre el tanque y el poblado más alejado hay un desnivel de -60 metros (INEGI 2000).

La figura 5 ilustra la distribución espacial del sistema y es útil para entender su manejo. La sección uno inicia en el manantial y termina en el tanque principal ubicado en Cuesta Blanca, la red de tubería que conduce el agua hacia el tanque de almacenamiento mide 10.2 kilómetros y el tubo es de 12 y 10 pulgadas de diámetro. La sección dos se conforma por la red principal de distribución que va desde el tanque de Cuesta Blanca hasta Pozuelos, la localidad más alejada, dicha tubería tiene una longitud de 18 kilómetros, su diámetro inicial es de 8 pulgadas y disminuye hasta terminar en 4 . 

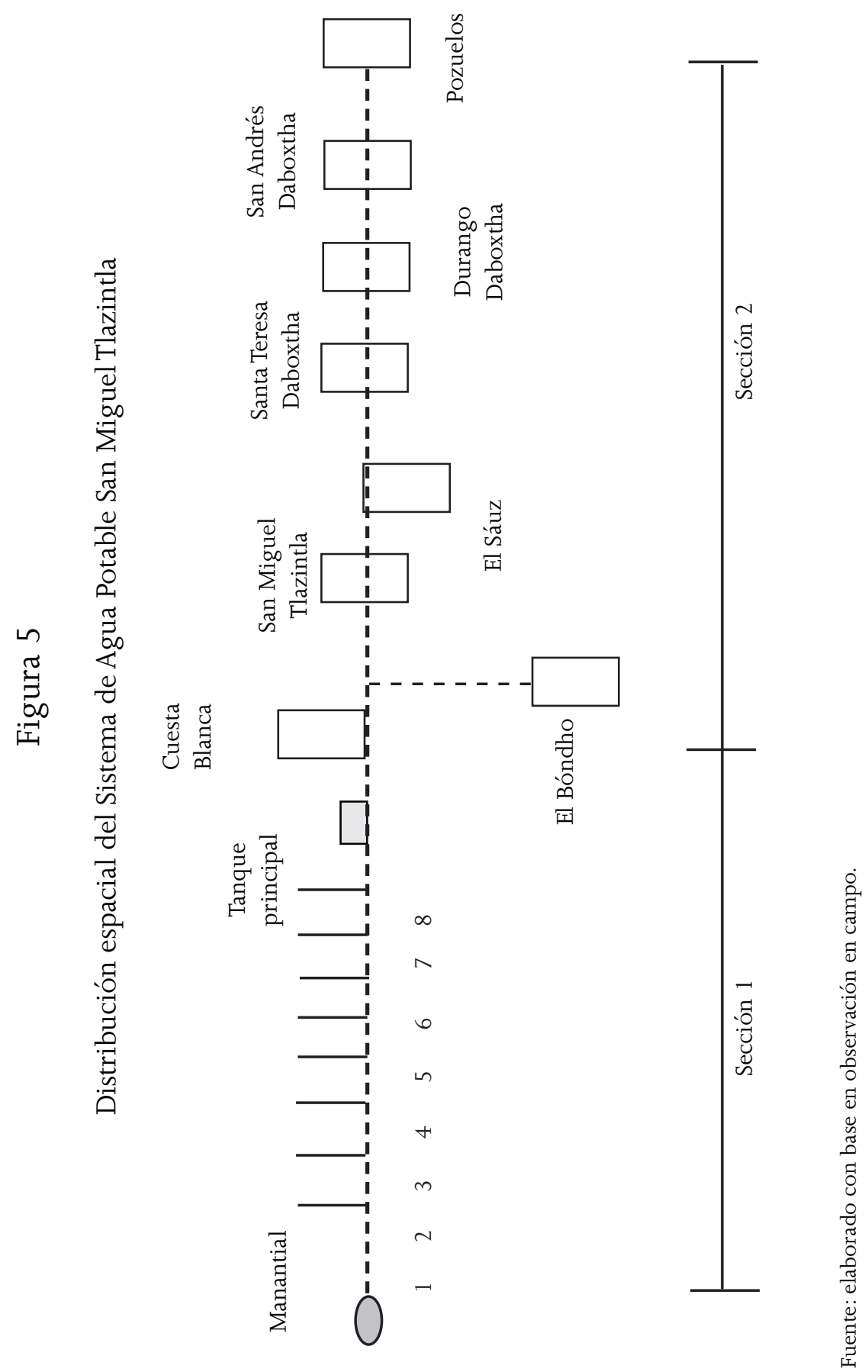
Antecedentes del abasto de agua entubada

Según la memoria histórica del sistema de agua potable, en 1954 los usuarios solicitaron apoyo al Patrimonio Indígena del Valle del Mezquital para conducir el agua de un manantial denominado El Pinal, pero fue en 1969 cuando el agua traída desde el manantial Salinas, a través de la línea de tubería, llegó a Cuesta Blanca (Hernández y Cruz 2007).

La SRH reportó que en 1961 se inició la construcción de las obras para abastecer a las localidades de El Pinal, San Miguel Tlazintla, El Sáuz, San Andrés Daboxtha y Santa Teresa Daboxtha, e indica que se captó el manantial El Pinal, cuyo gasto promedio era de 0.5 litros por segundo, que se instaló la línea de conducción, la red de distribución y que se construyeron "[...] seis hidrantes públicos, un abrevadero y se conectaron cuatro tanques superficiales de mampostería de $10 \mathrm{~m}^{3}$ de capacidad construidos con anterioridad por el Pivm, en donde surtían el agua por medio de pipas, beneficiando con ello a una población de 3500 habitantes y 4000 cabezas de ganado" (SRH 1961, 31).

Este primer intento no dio los resultados esperados por el poco volumen aportado por el manantial El Pinal, por lo que en el de 1965 los usuarios se propusieron traer el agua desde el de Salinas y con el apoyo del profesor Maurilio Muñoz Bacilio, vocal del PrvM, las localidades beneficiadas recibieron la totalidad de tubería requerida para conducir el agua hasta Cuesta Blanca (Hernández y Cruz 2007).

En 1968 se dividió en ocho partes o tramos la primera sección del sistema y se repartieron a las localidades beneficiadas para que, con trabajo comunitario, hicieran la brecha por donde ahora pasa la tubería (Ibid.). El orden asignado y que aún prevalece está en función de la distancia que hay entre cada poblado y el manantial: Cuesta Blanca, tramo 1; El Bóndho, 2; San Miguel Tlazintla, 3; El Sáuz, 4; Santa Teresa, 5; Durango, 6; San Andrés, 7 y Pozuelos, 8. En 1969 los usuarios terminaron de instalar la tubería en la primera sección, la cual comprende $10.2 \mathrm{~km}$, y el agua del manantial Salinas llegó a Cuesta Blanca y un año después conectaron la tubería del sistema El Pinal que estaba en desuso (Ibid.). 
Situación actual

Este sistema no tiene una concesión que garantice sus derechos de aguas, y los diez comités de usuarios que intervienen en su manejo están al margen de los requerimientos de la legislación vigente en materia de aguas.

Su dirección oficial es Tanque General, domicilio conocido, Cuesta Blanca, Cardonal, Hidalgo, y la de la oficina general es Domicilio conocido, El Sáuz, Cardonal, Hidalgo. Los bienes propiedad del sistema son: un predio de $400 \mathrm{~m}^{2}$, adquirido en 1995, donde se localiza el manantial; otro de diez hectáreas, comprado en 1999, y es una zona boscosa contigua al manantial; las oficinas generales, construidas en 2001, y el predio donde se ubican, que se adquirió en el año 2000; un predio más de $1200 \mathrm{~m}^{2}$, ubicado en la manzana El Molino, perteneciente a San Miguel Tlazintla, y adquirido en 2008, para la futura perforación de un pozo profundo, que beneficiará a las ocho localidades.

Como se indica en la figura 6, hasta diciembre de 2008 el sistema abastecía 278 tomas públicas y 1697 domiciliarias. La primera categoría se refiere a las viviendas que reciben agua del sistema,

\section{Figura 6}

Tomas servidas por el Sistema de Agua Potable San Miguel Tlazintla

\begin{tabular}{|l|c|c|c|}
\hline Comunidad & Tomas domiciliarias & Tomas públicas & Total \\
\hline Cuesta Blanca & 84 & 17 & 101 \\
\hline El Bóndho & 76 & 23 & 99 \\
\hline San Miguel Tlazintla & 368 & 59 & 427 \\
\hline El Sáuz & 353 & 8 & 361 \\
\hline Santa Teresa Daboxtha & 218 & 14 & 232 \\
\hline Durango Daboxtha & 139 & 0 & 139 \\
\hline San Andrés Daboxtha & 337 & 46 & 383 \\
\hline Pozuelos & 122 & 111 & 233 \\
\hline Total & 1697 & 278 & 1975 \\
\hline \multicolumn{2}{|c|}{ Fuente: elaborado con información proporcionada por el presidente del Comi- } \\
té General de Administración.
\end{tabular}


pero en hidrantes públicos o directamente de los tanques de almacenamiento, y la segunda a las que cuentan con el servicio de agua entubada. Ambas categorías fueron establecidas por los usuarios, al igual que la cuota por el servicio de agua entubada, y que asciende a 120 pesos por año en las tomas domiciliarias y 60 en las públicas.

Estructura administrativa

En la figura 7 es posible ver que para la administración del sistema de agua potable existe un comité local, uno general de administración y un consejo de vigilancia, que se integran con usuarios de las ocho localidades y su delegado municipal. Todos los cargos son honoríficos y se rotan cada dos años, los integrantes de los comités locales y el delegado municipal se eligen en asamblea general de la comunidad respectiva, y se rotan entre los habitantes de cada una. Por su parte, los miembros de los dos comités generales se eligen en asamblea general de usuarios, y se rotan entre los usuarios de las ocho localidades.

Las actividades de los comités así como los derechos y obligaciones de los usuarios se rigen por un reglamento interno que han elaborado los propios usuarios, y que modifican de acuerdo a las necesidades del sistema; el vigente se reformó en 2007, y establece en sus artículos 8,9 y 10 que el comité general y los ocho locales se deben elegir y tomar posesión del cargo el primero y segundo domingo del mes de febrero respectivamente, y que el comité del consejo de vigilancia debe ser electo y tomar posesión a la mitad del periodo administrativo del comité general (Comisión de usuarios de los ocho pueblos 2007, 3).

Para ser integrante de alguno de los comités, el aspirante debe cubrir los siguientes requisitos: ser de nacionalidad mexicana, tener entre 25 y 57 años de edad, ser usuario del sistema por un periodo mínimo de siete años consecutivos, haber desempeñado cargos de manera satisfactoria en su comunidad y al momento de la elección no trabajar en el ayuntamiento municipal (Ibid., artículos 11, 12 y 13). El proceso y las reglas para la elección de los miembros son las siguientes: 


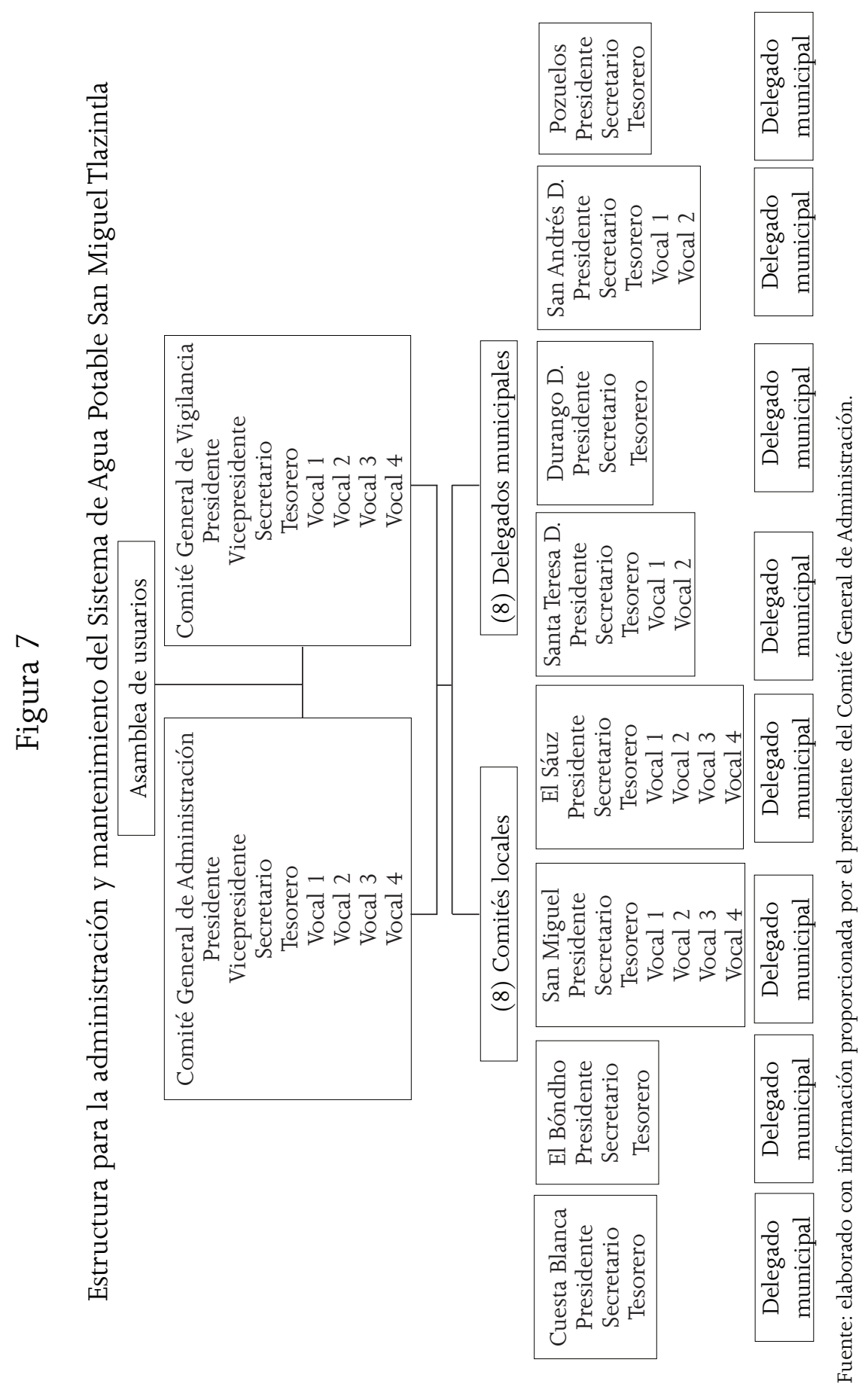


Artículo 14. El Consejo de vigilancia en conjunto con los Comités locales y Delegados municipales, publicarán la convocatoria para la elección del Comité general y Consejo de vigilancia con tres meses de anticipación; Artículo 15. Los candidatos a integrar el Comité general deben ser registrados por su Comité local y Delegado municipal, con un mes de anticipación $[\ldots]$ habiendo desempeñado como mínimo el cargo de Delegado municipal o Comité local del agua; Artículo 16. El Comité general a través de los Delegados municipales promoverá la elección de los Comités locales con tres meses de anticipación, de acuerdo a las normas internas de cada comunidad y sin contravenir los artículos 11 , 12 y 15 del reglamento; Artículo 17. La elección del Comité general y del Consejo de vigilancia se realizarán por los usuarios en asamblea general y podrán votar mediante el siguiente procedimiento: a). Los usuarios titulares o en su representación los cónyuges, hijos o hijas mayores de edad que aún dependan de sus padres, b). Presentar identificación con fotografía del usuario, acompañada de la última tarjeta de pago, misma que se le pondrá el sello de vото, c). Se utilizará tinta indeleble en el dedo pulgar de la mano derecha, y en la segunda ronda en el dedo pulgar de la mano izquierda, para no representar a mas de un usuario, d) Los usuarios que tienen más de una toma, tendrán derecho a un solo vото, sellándose las tarjetas que presente aunque corresponda a comunidades diferentes; Artículo 18. Las elecciones serán presididas por una mesa de debates que se integrará por un presidente, secretario y tres escrutadores, nombrados de entre los usuarios presentes en el momento de las elecciones; Artículo 19. El proceso electoral tanto para el Comité general como para el Consejo de vigilancia se llevará acabo en dos etapas como sigue: a) En la etapa preeliminar, se elegirán de entre ocho candidatos, a los cuatro que ocupen el mayor número de votos, quienes pasarán a contender en una segunda etapa, para ocupar los cargos de Presidente, Vicepresidente, Secretario, y Tesorero, de acuerdo al número de votos emitidos en su favor, b) Los cuatro candidatos que queden con menor número de votos en la etapa preeliminar, ocuparán los cargos de 1ro., 2do., 3ro., y 4to., vocal de acuerdo al número de votos emitidos a su favor, c) Los votantes deposi- 
tarán su voto de manera directa y abierta, mediante una raya al frente del nombre de su candidato favorito (Ibid., 4).

Actividades de los comités

Las responsabilidades asignadas a cada comité y a los delegados municipales son: celebrar una reunión ordinaria el primer domingo de cada mes y las extraordinarias que sean convenientes; llevar un control en los trabajos de mantenimiento del sistema, para esto se han establecido dos calendarios o roles de trabajo, uno de recorridos por la tubería de la sección; uno del sistema y otro de trabajo comunitario o faenas.

El primero es para que los representantes de cada comunidad que ocupan cargos en los comités realicen un recorrido mensual para la inspección de la línea de tubería y la brecha por donde pasa; el segundo para llevar un control de las faenas o trabajo comunitario que cada usuario realiza para el sistema, y cuando una comunidad agota su número de usuarios inscritos en el padrón, las faenas sucesivas las desempeña la comunidad que sigue en el rol. Este orden continúa así hasta que les toca a los ocho pueblos.

El recorrido se lleva acabo una semana antes de la reunión mensual ordinaria, a quienes les toca tal actividad deben hacer un reporte escrito en el que indiquen los desperfectos encontrados en cada una de los ocho tramos de la primera sección. Ya en la reunión mensual, el comité general determina el número de usuarios que se necesitan para reparar los desperfectos, y en la misma sesión lo comunican al representante de la comunidad en turno del rol de faenas, para que lo hagan saber a sus representados y ejecuten dicha tarea.

A los comités locales y los delegados municipales también les corresponde ejecutar el calendario de trabajo para la inspección mensual de la primera sección del sistema, así como la asignación de nuevas tomas de agua, coordinar el mantenimiento del tramo de la red principal que está dentro de los límites territoriales de su comunidad, recolectar la tarifa anual que se cobra por el servicio de agua entubada y aplicar las sanciones establecidas en el reglamento interno. Además, es su obligación coordinar una faena para que cada comunidad realice el mantenimiento necesario al tramo 
que se le ha asignado en la primera sección del sistema y efectuar un mínimo de tres recorridos al año, para verificar el estado de la red principal de distribución y de las domiciliarias en la sección dos. Durante estos recorridos se revisan las instalaciones de cada vivienda que cuenta con toma doméstica, y se reportan por escrito los casos que ameriten una sanción.

Los artículos 53 y 36 del reglamento interno del Sistema de Agua Potable San Miguel Tlazintla (Ibid., 6) especifican que, para ingresar a un domicilio a revisar las instalaciones hidráulicas, los integrantes del comité deben tener la autorización de una persona mayor de edad o, en su defecto, hacerse acompañar de las autoridades de la localidad correspondiente.

Al presidente y tesorero del comité general les corresponde, previa autorización del presidente del consejo de vigilancia, realizar las compras de materiales y equipos necesarios para el buen funcionamiento del sistema, y solventar los gastos que se generan cuando se solicitan apoyos a la presidencia municipal o al gobierno estatal.

\section{Requisitos para ser usuario}

El reglamento interno define dos categorías de usuarios, los nacidos en cualquiera de las ocho comunidades y los no nacidos en alguna de ellas; en su artículo 67 (Ibid., 9), indica que las personas que se encuentren en el segundo caso, y soliciten una toma de agua deben pagar el equivalente a 900 salarios mínimos del vigente en la región, y que el dinero recabado por ese concepto se quedará en la tesorería del comité local, a la que pertenecerá el futuro usuario. Para los originarios del lugar que tengan la mayoría de edad y que por ausencia no hayan cumplido con el sistema, el artículo 68 del reglamento (Ibid.) establece que deberán pagar los años de adeudo al monto de las tarifas vigentes y el equivalente a cooperaciones monetarias y faenas que se hayan realizado durante su ausencia. Además de lo anterior, todos los usuarios del sistema deben cumplir con las siguientes disposiciones:

Artículo 42. Todo usuario debe realizar las faenas que el Comité general considere convenientes de acuerdo a los trabajos (de- 
sastres o cambios de tubería en tramos largos, etc); Artículo 43. Todo usuario debe notificar a la autoridad correspondiente cualquier desperfecto o mal uso que se detecte en la línea de agua, ramales, hidrantes y depósitos; Artículo 44. Todo usuario deberá desempeñar el cargo o puesto que su comunidad le encomiende con relación al sistema [...]; Artículo 45. Todo usuario(a) que alcance la edad de 60 años queda exento de pago de cooperaciones, reuniones y faenas para lo cual las autoridades de su comunidad emitirán una constancia que autorice y avale la edad del usuario(a), el interesado(a) justificará con acta de nacimiento original sin manchas ni correcciones al Comité local, con copia al Comité general; Artículo 46. Cuando en una familia haya integrantes que obtengan la mayoría de edad en el hogar paterno pagarán al 100\% el servicio, asumiendo todas las obligaciones con el sistema y los usuarios que se sirvan con sistema de bombeo pagarán su servicio al 50\%; Artículo 47. Toda madre soltera o viuda, tendrá la obligación de integrarse al sistema siempre y cuando viva en la comunidad en forma permanente, aún no teniendo domicilio; Artículo 48. Las madres solteras o viudas que hagan uso del servicio en hidrante público, quedan exentas de faenas, pero no así del pago del servicio; Artículo 49. Toda madre soltera o viuda, cuando uno de sus hijos alcance la categoría de ciudadano éste asumirá la responsabilidad de las obligaciones y derechos ante el sistema de agua potable (excepto estudiantes); Artículo 50. Todo usuario tendrá la obligación de votar en todas las elecciones; $[\ldots]$ Artículo 70 . Todo usuario que quiera construir su cisterna $[\ldots]$ será con una capacidad máxima de 8000 litros $[\ldots]$ será construida a nivel de tierra para detectar posibles fugas subterráneas; Artículo 71. Hacer conciencia y establecer compromiso entre todos los miembros de la familia para dar buen uso al agua considerando las siguientes recomendaciones: [...]; d) se podrán lavar vehículos mediante mecanismos adecuados quedando prohibido el lavado a chorro libre de manguera o a cubetazas; e) todo usuario que tenga la necesidad de establecer fábricas, invernaderos, granjas, baños públicos, o cualquier establecimiento que requiera agua, deberá justificar mediante recibos o facturas certificadas por sus autoridades locales; 
Artículo 72. El usuario podrá hacer uso del agua potable para sus animales siempre y cuando que no sea granja debidamente establecida, ajustándose a las siguientes cantidades: a) 10 animales grandes entre reses, caballo y/o burros; b) 30 borregos, 10 puercos y 100 aves. Con la modalidad para quien no desee tener animales grandes, podrá incrementar hasta 10 borregos o puercos; [...] Artículo 76. Todas las instituciones y organizaciones que proporcionan servicios a la comunidad tienen derecho a una toma de agua quedando exentos de pago, así mismo para las personas con incapacidad física para el trabajo, previo análisis de la asamblea comunitaria y acompañado de un dictamen médico (Ibid., 7, 9 y 10 ).

Situación financiera

Los comités locales y el delegado municipal se encargan de reunir las cuotas en su respectiva localidad y entregarlas al tesorero del comité general, pero el dinero recabado por concepto de multas y sanciones se queda en su tesorería. Hasta 2008, la recaudación de cuotas por el servicio de agua entubada era de 100 por ciento, y por el número de tomas servidas se obtuvieron 220320 pesos, esta cantidad más el saldo del año anterior de 42934 dio como resultado que el comité general manejara 263254 pesos durante todo el año. Los egresos totales sumaron 214665.50 al año, y se emplearon en la compra de materiales y gestiones de los comités ante dependencias públicas.

Así, el informe financiero del tesorero del comité general, que se leyó en público en la asamblea general de usuarios celebrada el 1 de febrero de 2009, arrojó un saldo de 48 588.50, tal cantidad, más 42 mil pesos que sobraron de las cooperaciones extraordinarias, fijadas durante la administración 2007-2008, sumaron 90588.50 pesos (véase figura 8) que se tenían en caja, cantidad que en la reunión de usuarios el comité general saliente le entregó al nuevo.

El superávit anual es resultado directo de que las tareas de administración y mantenimiento estén a cargo de los propios usuarios, y que se realicen con trabajo no remunerado. 


\section{Figura 8}

Sistema de Agua Potable San Miguel Tlazintla:

ingresos y egresos, ejercicio 2007-2008

\begin{tabular}{|c|c|c|c|c|}
\hline Tarifa (pesos) & Tomas & Ingresos (pesos) & Concepto & Egresos (pesos) \\
\hline Doméstica 120 & 1697 & 203640 & Gastos varios & 214665.50 \\
\hline Pública & 278 & 16680 & Egresos anuales & 214665.50 \\
\hline \multicolumn{5}{|c|}{ Ingresos anuales 220320.00} \\
\hline \multicolumn{5}{|c|}{$\begin{array}{r}\text { Saldo año anterior } 42934.00 \\
\text { Cooperaciones } 42000.00\end{array}$} \\
\hline & & & Sald & nual 90588.50 \\
\hline
\end{tabular}

Fuente: elaboración propia, con datos proporcionados por el presidente del Comité General de Administración.

Un dato que se obtiene de la figura 8 es el costo mensual que el titular de una toma servida paga por el servicio de agua entubada. Al dividir la cuota anual entre los 12 meses del año, él paga diez pesos al mes por el suministro de agua a su vivienda, y el titular de una toma pública paga cinco pesos mensuales por el derecho de asistir a un hidrante público o un tanque de almacenamiento a tomar el agua que necesite.

Con la información de esta sección se muestra que los pequeños sistemas administrados por organizaciones comunitarias, con rotación de cargos entre los usuarios, contribuyen a reducir los costos de operación. Por ello, en el Sistema de Agua Potable San Miguel Tlazintla el arreglo social de conformar comités y hacer el mantenimiento con el trabajo no remunerado de los usuarios permite eliminar el concepto de personal empleado. También se demuestra que a pesar de no poseer una personalidad jurídica reconocida por la legislación en la materia, las organizaciones que manejan dicho sistema tienen la capacidad de regular el uso de la infraestructura hidráulica y el agua que conduce. Cabe resaltar que para esto último los usuarios han formulado reglamentos escritos y establecen sanciones para garantizar el abasto del agua a través del tiempo.

Finalmente, se puede afirmar que las organizaciones comunitarias diseñadas por los propios usuarios resultan informales ante 
las dependencias gubernamentales. Pero, también que tales arreglos institucionales son reconocidos y legitimados por ellos mismos, así como las organizaciones creadas por los usuarios del Sistema de Agua Potable San Miguel Tlazintla resultan eficientes y legítimas dentro de las comunidades abastecidas.

\section{Organismo operador versus comité de usuarios Selección del personal}

En el organismo operador, el alcalde en turno, en su calidad de presidente de la Junta de gobierno, toma las decisiones respecto a quiénes y por cuánto tiempo ocuparán los puestos administrativos y operativos para el manejo del sistema, y fija el monto de los sueldos devengados por el personal empleado. En el sistema manejado por los usuarios, los integrantes de los ocho comités locales se eligen mediante voto directo en las respectivas asambleas comunitarias, y quienes integran el comité de administración y el consejo de vigilancia se eligen en una asamblea general de usuarios en la cual vota el titular de cada toma servida.

Las atribuciones de los administradores y operarios del organismo operador emanan de la legislación nacional y estatal en materia de agua para uso doméstico, del bando de buen gobierno municipal y de los acuerdos que tome su Junta de gobierno. Por el contrario, las atribuciones y el área geográfica que manejan los dos comités generales y los ocho locales están establecidas en un reglamento elaborado por los propios usuarios, para el cual se toma como base la situación particular del sistema y se reforma de acuerdo con los cambios y necesidades del mismo.

Acceso al servicio y derechos y obligaciones de los usuarios

En las ocho localidades abastecidas por el Sistema de Agua Potable San Miguel Tlazintla, los usuarios establecieron como una obligación hacer trabajo comunitario o faenas para su mantenimiento, incluso se antepone este tipo de labor al pago anual por el servicio de 
agua entubada como requisito principal para acceder y permanecer como usuario del sistema. En el organismo operador, los requisitos son solicitar y firmar el contrato respectivo y cubrir en tiempo y forma el pago de la tarifa mensual establecida.

Tipo y monto de las tarifas

El Congreso de Hidalgo aprobó las tarifas doméstica y comercial, las cuales se cobran cada mes sin importar que en siete de ocho localidades servidas el abasto de agua se haga según un calendario de tandeo, que sólo proporciona agua entubaba cada tres días. En el Sistema de Agua Potable San Miguel Tlazintla se establecieron dos categorías de usuarios: domiciliario y público, ambas tienen agua las 24 horas del día y la tarifa estipulada, también por los usuarios, se paga en forma anual.

Situación financiera y capacidad

para cubrir los gastos fijos con sus ingresos fijos

La recaudación de las cuotas por el servicio de agua entubada es de 100 por ciento en las dos organizaciones que se estudiaron, pero su situación financiera es diferente. En el organismo operador los ingresos fijos apenas cubren 31.68 por ciento de los gastos fijos, y no son suficientes ni para pagar los sueldos del personal empleado. Para revertir tal situación, cada toma servida debería pagar 162 pesos por mes, un precio demasiado alto si se considera el actual de 50 de las tomas domésticas, y que por esa cantidad sólo una de las ocho comunidades tiene el servicio todos los días de la semana.

La fuente de agua del Sistema de Agua Potable San Miguel Tlazintla es un manantial, y la captación y distribución del líquido a la totalidad de tomas se hace con la fuerza de gravedad, ello contribuye de manera directa para disminuir los costos, pero también el hecho de que la administración y el mantenimiento se haga con trabajo no remunerado. Bajo tales circunstancias, los usuarios de este sistema, que tienen agua entubada en sus viviendas, pagan diez pesos por mes y sólo cinco los que se abastecen en los tanques de almacenamiento o hidrantes públicos. 
Tales diferencias entre las organizaciones tienen una explicación, y es la decisión social que se toma para manejar los sistemas de agua potable en cuestión. Así, los usuarios del Sistema de Agua Potable San Miguel Tlazintla prefieren manejarlo por sí mismos y para ello aportan trabajo no remunerado. Por el contrario, el Ayuntamiento de El Cardonal decidió conformar un organismo operador para el manejo del sistema a su cargo, lo que implica que cada mes se sustraiga dinero del erario municipal para subsidiar el consumo de agua de ocho localidades en un municipio que tiene 92 en su territorio.

\section{Conclusiones}

La información del documento permite concluir que la legislación nacional y estatal condicionan la participación de los usuarios en el manejo de pequeños sistemas de agua entubada, toda vez que los obligan a constituir sus organizaciones como una persona moral. Y, en el caso concreto del estado de Hidalgo, la participación de los usuarios se condiciona a que el ayuntamiento y el Congreso respectivo les otorgue una concesión para el manejo de un sistema en específico.

Con la información obtenida en el municipio de El Cardonal, se concluye que el manejo de pequeños sistemas de agua potable por organismos operadores no resulta adecuado en todos los casos. Ya que sin los subsidios municipales ese manejo de tipo gerencial, emanado de la legislación vigente, es insostenible en el largo plazo. En el caso específico del organismo de El Cardonal, para eliminar el subsidio, con los actuales costos de personal, sería necesario elevar el monto de las tarifas, y para ello se necesita la aprobación del Congreso estatal.

Para el Sistema de Agua Potable San Miguel Tlazintla se concluye que el arreglo institucional, que consiste en conformar comités comunitarios y multicomunitarios, resulta adecuado y legítimo ante los usuarios, ya que al tiempo que elimina los costos de administración hace eficiente su manejo y garantiza el abasto de agua en el largo plazo. 
A partir de lo expuesto en este trabajo, sólo queda decir que sería conveniente que la legislación en materia de aguas apoyase las soluciones puestas en marcha, ya que son de bajo costo, satisfactorias para los usuarios y hacen posible el manejo local de los pequeños sistemas de agua potable.

Recibido en agosto de 2011 Aceptado en enero de 2012

\section{Bibliografía}

Aboites Aguilar, Luis. 1998. El agua de la nación: una historia política de México 1888-1946. México: CIESAS.

Aguirre Beltrán, Gonzalo. 1994. Programas de salud en la situación intercultural. México: Fondo de Cultura Económica (FCE).

1992. Teoría y práctica de la educación indígena. México: FCE.

Agarwal, Anil, Sunita Narain e Indira Khurana (editores). 2001. MakingWater Everybody's Business. Practice and Policy of Water Harvesting. India: Centre for Science and Enviroment.

y Sunita Narain (editores). 1991. DyingWisdom. Rise, Fall and Potential of Indias Tradicional Water Harvesting Systems. India: Centre for Science and Environment.

Birrichaga, Diana. 2007. Modernización del sistema hidráulico rural en el Estado de México (1935-1940). En La modernización del sistema de agua potable en México 1810-1950, coordinado por ídem., 193-217. México: El Colegio Mexiquense.

Bribiesca, José Luis. 1959. El agua potable en la república mexicana, sexta parte: los abastecimientos en la época actual: 1920-1960. Ingeniería Hidráulica en México Iv (13): 97-110. 
Burguete, Araceli. 2001. Agua que nace y muere:sistemas normativos indígenas y disputas por el agua en Chamula y Zinacatán. México: Instituto de Investigaciones Antropológicas, Universidad Nacional Autónoma de México (unam).

Comisión de usuarios de los ocho pueblos. 2007. Reglamento interno del Sistema de Agua Potable San Miguel Tlazintla, documento mimeografiado, El Sáuz, El Cardonal, Hidalgo, México.

CONAGUa. 2011. Registro público de derechos de agua. http: //www. conagua.gob.mx/REPDA/anexos.aspx?Id=13 HGO1 05648/26HMGE $03|0| 2 \mid$ S (30 de junio de 2011).

2010. Manual de operaciones y procedimientos del programa para construcción y rehabilitación de sistemas de agua potable y saneamiento en zonas rurales. México: CONAGUA.

2004. Ley de Aguas Nacionales 1992. En Ley de Aguas Nacionales y su reglamento, editado por ídem., 1-119. México: ConAGUA.

2004. Reglamento de la Ley de Aguas Nacionales. En Ley de Aguas Nacionales y su reglamento, editado por ídem., 123-206. México: CONAGUA.

1994. Ley de Aguas Nacionales 1992. En Ley de Aguas Nacionales y su reglamento, editado por ídem., 9-73. México: CONAGUA.

1994. Reglamento de la Ley de Aguas Nacionales. En Ley de Aguas Nacionales y su reglamento, editado por ídem., 75-174. México: CONAGUA.

COPLAMAR. 1980. Convenio que establece el programa SAHOP-COPLAMAR de agua potable y caminos para zonas marginadas. México: CoPLAMAR.

De Laveleye, Emile. 1878. Primitive Property. Reino Unido: Mc Millan and Co. 
Hernández, Francisco y Martín Cruz. 2007. Memoria histórica del Sistema de Agua Potable San Miguel Tlazintla, documento mimeografiado, El Sáuz, El Cardonal, Hidalgo, México.

INEGI. 2011. XIII Censo general de población y vivienda. México: INEGI.

2000. Cartas topográficas escala 1:50 000, F14C69 y F14C79. México: INEGI.

INI. 1964. Memorias. Realidades y proyectos, 16 años de trabajo, volumen X. México: INI.

1955. Qué es el I.N.I. México: INI.

Köhler, Ulrich. 1975. Cambio cultural dirigido en los Altos de Chiapas: un estudio sobre la antropología social aplicada. México: INI y Secretaría de Educación Pública.

Lanz Cárdenas, José Trinidad. 1982. Legislación de aguas en México: estudio histórico-legislativo de 1521 a 1981, tomo 2. México: Consejo Editorial del Gobierno de Tabasco.

Maine, Henry. 1980. El derecho antiguo. España: Extemporáneos.

Marzal Fuentes, Manuel. 1968. La aculturación de los otomíes del Valle del Mezquital. Un intento de evolución del PIvм. Tesis de maestría en antropología social, Universidad Iberoamericana.

North, Douglass. 2006. Instituciones, cambio institucional y desempeño económico. México: FCE.

Ostrom, Elinor. 2000. El gobierno de los bienes comunes: la evolución de las instituciones de acción colectiva. México: UNAM-FCE.

Pineda Pablos, Nicolás. 2002. La política urbana de agua potable en México: del centralismo y los subsidios a la municipalización, la autosuficiencia y la privatización. región y sociedad xIv (24): 41-69. 
POEH. 2000. Reglamento de la Ley Estatal de Agua Potable y Alcantarillado para el Estado de Hidalgo. http:/ / www.ceaa-hidalgo.gob. mx/MarJur/MarJuridi.html (30 de junio de 2011).

1999. Ley Estatal de Agua Potable y Alcantarillado para el Estado de Hidalgo. http://www.ceaa-hidalgo.gob.mx/MarJur/ MarJuridi.html (30 de junio de 2011).

Procuraduría Agraria. 1993. Ley Agraria 1992. En Legislación agraria, editado por ídem., 39-106. México: Procuraduría Agraria.

SAHOP.1981. Acuerdo por el que la SAHOP procederá a entregar a los gobiernos de los estados y a los ayuntamientos todos los sistemas de agua potable y alcantarillado que administra y opera. [1980]. En Entrega de los sistemas de agua potable y alcantarillado a los gobiernos de los estados, fortalecimiento del federalismo, editado por ídem., 11-16. MéxiCO: SAHOP.

SEGOB-HGO. 2004. Quinto informe de gobierno de Manuel Ángel Núñez Soto. Estado de Hidalgo.

Smith, Adam. 2000. Naturaleza y causa de la riqueza de las naciones. México: FCE.

SPP. 1985a. Antología de la planeación en México 1917-1985, tomo 1. Los primeros intentos de planeación en México 1917-1946. México: FCE.

1985b. Antología de la planeación en México 1917-1985, tomo 2. La programación de la inversión pública y la planeación regional por cuencas hidrográficas 1947-1958. México: FCE.

SRH. 1976. La obra hidráulica de México a través de los informes presidenciales, volumen II. México: SRH.

1961. Agua potable, Hidalgo. México: SRH.

SSA. 1965. Agua potable rural. México: SSA. 
Tena Ramírez, Felipe. 2002. Artículo 115 constitucional reformado

el 3 de febrero de 1983. En Leyes fundamentales de México 1808-2002, compilado por ídem., 1018-1027. México: Editorial Porrúa.

Wade, Robert. 1988. Village Republics: Economic Conditions for Collective action in South India. Cambridge: Cambridge University Press. 